\title{
POLÍTICAS CRIMINAIS DE DESENCARCERAMENTO: ALTERNATIVAS A PARTIR DA ESCOLA DE CHICAGO
}

\section{Claudio Alberto Gabriel Guimarães ${ }^{1}$ Thayara Castelo Branco ${ }^{2}$}

RESUMO: Pretende-se com este trabalho, a partir do construído pela Escola Sociológica de Chicago, atualizar e resgatar os aportes teóricos que indicam o espaço urbano como fator inibidor ou potencializador da atividade criminosa, dependendo do seu nível de organização social e urbanística. Serão investigadas, também as possibilidades de implementação de políticas públicas de segurança (também em nível municipal), em uma perspectiva preventiva e inclusiva, que fora do âmbito reativo e repressivo sejam capazes de minimizar o estado de violências.

PALAVRAS-CHAVE: Escola de Chicago; desorganização urbana; Municípios; políticas públicas; desencarceramento.

\section{CRIMINAL DEINCARCERATION POLICIES: ALTERNATIVES FROM CHICAGO SCHOOL}

\begin{abstract}
The aim of this work is, based on what was built by the Chicago Sociological School, to update and rescue the theoretical contributions that indicate urban space as an inhibiting or potentializing factor of criminal activity, depending on its level of social and urban organization. The possibility of implementing public security policies (also at the municipal level), from a preventive and inclusive perspective, that outside the reactive and repressive scope will be able to minimize the state of violence will be investigated.
\end{abstract}

KEYWORDS: Chicago School; urban disorganization; Counties; public policy; deincarceration.

\footnotetext{
${ }^{1}$ Promotor de Justiça do Estado do Maranhão. Especialista em Direito, Estado e Sociedade pela Universidade Federal de Santa Catarina. Especialista em Docência Superior pelo Centro Universitário do Maranhão - UNICEUMA. Mestre em Direito Público pela Universidade Federal de Pernambuco. Doutor em Direito Público pela Universidade Federal de Santa Catarina, com área de concentração em Direito Penal. Doutor em Direito pela Universidade Federa de Santa Catarina, com área de concentração em Criminologia Professor Pesquisador do CNPq e UNICEUMA. Professor Adjunto da Universidade Federal do Maranhão. EMAIL: calguimaraes@yahoo.com.br.Endereço: Rua Domingos Rodrigues, n. 85, Bairro. Olho D'água. Cep: 65065-150. São Luis/MA

2 Doutora em Ciências Criminais pela PUCRS, com área de pesquisa em Violência, Crime e Segurança Pública (2016). Mestra em Ciências Criminais pela PUCRS, com linha de pesquisa em Criminologia e Controle Social (2010). Especialista em Ciências Criminais pelo CESUSC (2008). Professora da graduação e da pós-graduação da Univ. CEUMA. Coordenadora da Pós-Graduação em Ciências Criminais da Univ. Ceuma. Pesquisa sobre Ciências Criminais e Direitos Humanos. Advogada. Email: thaybranco@yahoo.com.br. Endereço: Rua dos juritis, n. 07, Condomínio Lagoa Azul, apto 803. Jardim Renascença. São Luis/MA. CEP: 65075-240
} 


\section{INTRODUÇÃO}

Atualmente os estudos em segurança pública e combate à violência passaram a ter um espaço importante na academia, gerando sérias controvérsias argumentativas sobre esse objeto. Isso porque, a sociedade assolada por uma cultura do medo e por uma realidade de violência extrema, clama por agendas governamentais rápidas e eficazes, capazes de sanar tal cenário. O Estado, por sua vez, por não priorizar tal agenda, apresenta políticas gourmetizadas, com receitas prontas e superficiais que atendem a um populismo punitivo que se agrava diariamente.

Esse é um cenário caótico e complexo que pretendemos tecer algumas considerações, a partir do seguinte problema: A partir da Escola sociológica de Chicago é possível construir novas formas de enfrentamento às violências urbanas por vieses menos reativos e repressivos e mais preventivos e inclusivos?

A Escola Sociológica de Chicago, dando ênfase aos estudos das e nas cidades $^{3}$, sistematiza que, em geral, o crime é um produto da desorganização social e urbana, resultado de problemas institucionais tanto na esfera pública quanto privada, sustentando, portanto, que o crime se origina de déficits na esfera do controle social informal - família, escola, laços comunitários, religião, etc. - e na esfera da urbanização - áreas urbanas sujas, fétidas, degradadas, abandonadas pelo poder público, etc. - e não uma patologia individual.

Dando ênfase às pesquisas de campo, privilegiando o empirismo pela via da pesquisa qualitativa, os sociólogos de Chicago, ao estudarem a criminalidade, perceberam que os ambientes socialmente desorganizados estavam fortemente encravados em locais com deficiências no planejamento e desenvolvimento urbanos, se configurando como as áreas onde as estatísticas apontavam os maiores índices de cometimento de determinados tipos de crimes, mormente os violentos.

No presente trabalho objetivamos discorrer sobre um dos consistentes marcos teóricos desenvolvidos sobre a criminalidade e formas de enfrentá-la, mais precisamente, sobre o que produzido nessa área pela sociologia da Escola de Chicago

\footnotetext{
${ }^{3}$ Um dos mais renomados sociólogos de Chicago, Park (1967, p. 12) percebia a cidade como um laboratório para a investigação da vida social. Nas suas próprias palavras "hoje, o mundo inteiro ou vive na cidade ou está a caminho da cidade; então, se estudarmos as cidades, poderemos compreender o que se passa no mundo".
} 
desde os idos do início do século passado para, a partir de tal estudo, atualizar e verificar o que pode ser utilizado nas interpretações dos fenômenos sociais hodiernos.

Assim, alicerçados no método bibliográfico, buscando uma ampla revisão das obras clássicas, assim como, para atualização da abordagem, do que mais recentemente foi escrito sobre a temática, pretendemos discorrer sobre a perspectiva teórica adotada pela sociologia de Chicago para tentar explicar (de forma não positivista) alguns fenômenos criminais e, consequentemente, sob a mesma perspectiva, a melhor maneira para enfrentar tais situações.

Aprofundar-se-á a pesquisa no sentido de investigar a atualidade da temática, tanto no sentido de cabimento atual das hipóteses defendidas por aquela sociologia, como de sua pertinência para investigação específica do fenômeno criminal no Brasil.

Assim sendo, este estudo justifica-se pela importância da análise acerca da possível consequência da adoção de políticas públicas de abrangência social como mecanismo de prevenção e combate à criminalidade, uma vez que, por meio da efetivação de instrumentos capazes de diminuir as profundas desigualdades sociais que se refletem por meio da desorganização social e urbana, em respeito mesmo aos princípios contidos no bojo da Constituição da República Brasileira, é que se poderá, fora do contexto reativo/repressivo, buscar soluções para as crescentes ondas de violência estrutural e violência criminal que estão a assolar o país e, consequentemente, diminuir os índices de encarceramento.

Para tanto, dividiu-se o estudo em três partes. Inicialmente apresentamos os aportes teóricos da Escola Sociológica de Chicago de maneira atualizada à realidade brasileira para, a seguir, apresentarmos estudos na esfera de desenvolvimento de políticas públicas de segurança na área preventiva e inclusiva e, por fim, apresentamos as possibilidades de implementação do saber produzido pela via das políticas públicas a serem desenvolvidas pelos municípios, cujo objetivo maior será centrado no efetivo combate à violência estrutural e, por esta via, da violência criminal com a consequente diminuição de ambas, assim como, e por via direta, dos níveis de encarceramento no Brasil. Este é o desafio do texto que se segue.

\section{APONTAMENTOS INICIAIS SOBRE A ESCOLA DE CHICAGO}


Primeiramente cabe fazer o destaque que, em razão do espaço, com respeito às exigências analíticas que o texto acadêmico requer, serão apresentadas no presente tópico apenas as ideias que, a nosso sentir, ainda se amoldam e têm aplicabilidade à realidade brasileira ${ }^{4}$ atual, tendo sido desprezadas várias teorias sociológicas desenvolvidas no âmbito da Escola agora em estudo, que se revelam anacrônicas pois não são aplicáveis, como por exemplo a dos círculos concêntricos de Burgess ${ }^{5}$.

Portanto, todas as ideias aqui expostas apresentam um estrato atualizado, que tem aplicabilidade a realidade que nos circunda nos dias de hoje ${ }^{6}$, não sendo objeto deste trabalho aprofundar a análise sobre tudo o que produzido pela Escola de Chicago, realizando uma confrontação teórica interna às suas teorias ou a crítica daquilo que entendemos não mais ser aplicável ao fenômeno criminógeno atual.

Essa é a razão pela qual, resgatamos a questão inicial do intenso pragmatismo que permeou tudo o que foi produzido por tal sociologia, devendo-se isto ao fato de que muitos dos professores de Chicago, como muitos dos primeiros sociólogos americanos, eram pastores protestantes profundamente comprometidos com reformas sociais, cujo interesse seria produzir saberes voltados para o equacionamento dos problemas sociais que afligiam as grandes cidades americanas. Assim sendo, à época, no Departamento de Sociologia da Universidade de Chicago, todos comungavam da posição de que algo precisava ser feito para enfrentar os graves problemas que afligiam a sociedade estadunidense, mormente aqueles ligados à pobreza ${ }^{7}$.

Deste modo, o empirismo que acaba por caracterizar a filosofia pragmática adotada pelos sociólogos em Chicago é marcado pela insistência de tais pesquisadores em produzir conhecimento que pudesse ser útil, tivesse aplicabilidade prática em prol do enfrentamento das dificuldades inerentes à estrutura social de então.

\footnotetext{
${ }^{4}$ Um trabalho acadêmico brasileiro que fez a devida conexão entre os ensinamentos da Escola de Chicago e o desenvolvimento de políticas públicas de prevenção ao crime no Brasil foi desenvolvido por Tangerino (2007).

${ }^{5}$ Para entendimento do assunto, cfr. Burgess (1970).

${ }^{6}$ Sobre a utilização das teorias sociológicas produzidas pela Escola de Chicago, por autores brasileiros, em relação à interpretação do fenômeno criminal no Brasil, Cfr. Massena (1986), Adorno (1990), Misse (1995), Joas (1999), Siqueira (2001), Sogame (2001), Felix (2002), Freitas (2002), Teodósio (2003), Cerqueira e Lobão (2004), Ferreira e Penna (2005), Diniz (2005), Braga e Gastaldo (2009), Batella e Diniz (2010), Evangelista (2012), Andrade et al (2013), Melhem (2013), Cabral de Lira (2014), Lira (2014), Delgado (2014), Casteletto (2014), Melo e Matias (2015), Ramos (2015), Lira (2015), Santos (2016).

${ }^{7}$ Assim, Joas (1999), Cfr., também, Park e Burgess (1921).
} 
Portanto, em razão da adoção de tal filosofia pragmática ${ }^{8}$ os estudos em Chicago acabam por voltar-se para a temática urbana e para o trabalho de campo. Nesse sentido, a Escola de Chicago se distancia da até então em voga sociologia especulativa, inaugurando o que viria a ser conhecida como uma sociologia da ação, de viés humanista, fortemente impregnada de valores religiosos e comprometida com a transformação social ${ }^{9}$.

Para alcance dos objetivos acima delineados, necessário que se desenvolvessem métodos de pesquisa aptos a auxiliar em tal propósito. Várias foram as inovações produzidas, sendo tributárias em maior ou menor medida, do desenvolvimento teórico denominado de interacionismo simbólico ${ }^{10}$, ou seja, novas metodologias de pesquisa passaram a ser desenvolvidas, ocorrendo uma verdadeira revolução na estrutura do método ${ }^{11}$.

Para os interacionistas, todo e qualquer método a ser desenvolvido deveria partir do ponto de vista dos agentes sociais, elucidando as significações que estes próprios põem em prática para construir seu mundo social. Nas palavras de Coulon (1995, p. 22), “É preciso preservar a integridade do mundo social para poder estudá-lo, e levar em conta o ponto de vista dos agentes sociais, pois é através do sentido que atribuem a objetos, indivíduos e símbolos que os rodeiam, que eles fabricam seu mundo social".

Entendiam os interacionistas que é a partir das interpretações do mundo que os rodeia, dos significados que provém das relações interativas dos agentes sociais relações de vizinhança, de trabalho, com o meio físico, ambiental, urbano, etc. - que estes determinam as suas condutas ${ }^{12}$.

Assim sendo, da junção de ideias oriundas da filosofia pragmática, enquanto filosofia da ação, com as ideias produzidas no âmbito do interacionismo simbólico, restou que os sociólogos de Chicago, por via óbvia, privilegiaram o trabalho da pesquisa de campo, como forma de melhor conhecer a cidade e seus moradores e,

\footnotetext{
${ }^{8}$ Sobre a Filosofia Pragmática, em profundidade, Dewey (2018). Cfr. Também, Nascimento (2010).

${ }^{9}$ Sobre o assunto, por todos, Coulon (1995, p. 17-18).

${ }^{10}$ Para aprofundamento na temática, cfr. seu principal teórico, Mead (1934).

${ }^{11}$ Sobre as influências produzidas pelo Pragmatismo sobre o Interacionismo Simbólico, cfr. Felgueiras (2016). Cfr. também, Thomas (1923).

${ }^{12}$ Para aprofundamento no tema, cfr., Blumer (1986, p. 85 e ss.).
} 
por este caminho metodológico, apresentar soluções para resolução dos problemas ali localizados.

No que pertine, especificamente, ao estudo da criminalidade, outro não foi o caminho, sendo necessário que ratifiquemos o papel central do estudo das cidades, enquanto aglomerações urbanas "organizadas", vez que é através de tais estudos que se torna possível a identificação de áreas com maior propensão para a prática de determinados tipos de delitos ${ }^{13}$.

Desta feita, foram estabelecidos os espaços da cidade através dos fenômenos da competição, sucessão e dominância, observando os pesquisadores que em determinados locais, com características bem delineadas, havia uma nítida propensão para o cometimento de crimes. Ademais, foi detectado que nesses locais encontrava-se o tecido social mais desgastado, com uma profunda desorganização social ${ }^{14}$ e controle social praticamente inexistente.

Importante frisar que a desorganização social, nos estudos realizados pelos sociólogos de Chicago, configura-se como um fator preponderante para o cometimento de delitos ${ }^{15}$. Tal desorganização social tem origem na desagregação da família, que tem impacto direto na desagregação comunitária. Assim sendo, sem que a família e a comunidade possam exercer um fundamental papel no controle social, de base ética e moral, sem que se possa impor, deste modo, aos seus membros um conjunto de regras comuns, teremos, consequentemente, um impacto considerável nos índices de criminalidade.

$\mathrm{Na}$ presente visão teórica, com o desenvolvimento urbano das cidades as camadas mais pobres ${ }^{16}$ da população foram sendo empurradas para a periferia, onde a urbanização era - e continua sendo - precária, configurando-se como áreas deterioradas, com infraestrutura absolutamente precária, tendo tal deslocamento causado a ruptura de

\footnotetext{
${ }^{13}$ Hodiernamente, tal perspectiva é amplamente utilizada, existindo até mesmo um software denominado RTM - Risk Terrain Model, que se propõem a fazer análise de risco de cometimento de delitos baseado em dados levantados em determinados locais. Maiores detalhes em Caplan (2016).

${ }^{14}$ Sobre o assunto, em profundidade, cfr. Thomas e Znaniecki (1927), Park e Mckenzie (1984).

${ }^{15}$ Um aprofundado estudo crítico sobre o conceito de desorganização social formulado pela sociologia de Chicago - de leitura imprescindível - pode ser encontrado em Bursik Jr. (1988, p. 534 e ss.).

${ }^{16} \mathrm{Em}$ tal seara, importante a observação feita por Tangerino (2007, p. 70), para quem: "Assim como seriam inadmissíveis relações diretas entre etnia e crime, também assim as relações de pobreza e crime. Entretanto, estar submetido a uma situação de pobreza é um componente ecologicamente relevante, pois serão os mais pobres a se verem obrigados a residir nas piores regiões, onde residem os autores das infrações criminais. Sobre as relações entre pobreza e criminalidade, em maiores detalhes, Ferreira e Penna (2005).
} 
seus laços familiares e comunitários ${ }^{17}$, dificultando o controle social informal, estabelecendo, assim, a somatória destas características, um profícuo caldo de cultura para o cometimento de crimes, mormente contra a pessoa, patrimoniais e de tráfico de drogas.

Em uma última análise, os sociólogos de Chicago perceberam que as condições acima descritas acabavam por atribuir uma péssima condição de vida às pessoas, obrigadas a viver em áreas fétidas, em meio ao lixo e esgotos a céu aberto, cuja convivência, por outro lado, era moldada por relações sociais conflituosas ${ }^{18}$, tributárias do baixo nível social que ali imperava, aliada, ainda, aos baixos salários oferecidos a mão de obra não qualificada daqueles que lá habitavam, criando tal ambiência de desorganização urbana ${ }^{19}$, abandono pelo poder público e consequente descontrole social, uma verdadeira ode à transmissão da cultura delinquente, denominada de tradição criminal ${ }^{20}$.

Aliado à importância do que até agora exposto, ou seja, a viragem metodológica para pesquisa da conduta humana, assim como a mudança de perspectiva para explicação da prática de atos criminosos, deve ser reconhecido à Escola de Chicago o mérito de apresentar outros meios, outras políticas para o combate de eixos de criminalidade mais sanguinária. $^{21}$

Nesse ponto, atribuímos importância as suas pesquisas e produção científica, vez que ao detectarem/denunciarem as péssimas condições de vida de determinada parcela da população como um dos fatores da criminalidade, apontaram como solução não opções repressivas, mas sim políticas públicas de inclusão social, pela via de recuperação urbana das áreas degradadas, assim como de medidas que combatessem a pobreza, a exclusão social, a falta de educação, enfim, que proporcionassem bem estar a toda a população ${ }^{22}$.

\footnotetext{
${ }^{17}$ A movimentação populacional intensa entre as diversas áreas da cidade, causada pelos fenômenos da dominância, sucessão e competição, rompe o contato e os laços entre os componentes de determinada comunidade e, até mesmo, laços familiares, enfraquecendo sobremaneira a possibilidade do controle comunitário e familiar sobre o indivíduo, tendo como consequência propiciar maiores índices de criminalidade na área invadida. Sobre o tema, em profundidade, Shaw e McKay (1942).

18 Sobre o papel das gangs em tal contexto, cfr. Cohen (2009).

${ }^{19}$ Uma atualizada pesquisa sobre relações entre crime e desordem urbana pode ser encontrada em Skogam (2014).

${ }^{20}$ Em maior profundidade, Dias e Andrade (1997).

21 Sobre a atualidade de tal perspectiva, cfr. Evangelista (2012)..

22 Sobre o tema, imprescindível conhecer o Chicago Area Project - CAP (2018).
} 


\section{POLÍTICAS CRIMINAIS INCLUSIVAS E PREVENTIVAS: UMA ANÁliSe DESCARCERIZANTE DE ENFRENTAMENTO À VIOLÊNCIA}

É pacífico que o controle social formal é uma atribuição exclusiva do Estado, embora ações que venham a objetivar um melhor disciplinamento no seio da sociedade não sejam exclusivas de órgãos públicos. Entretanto, compactuamos com a ideia segundo a qual a intervenção pública pela via da elaboração, planejamento e execução de políticas públicas na área da segurança sejam imprescindíveis para o alcance de índices mínimos de sociabilidade na convivência intersubjetiva.

Necessário, porém, romper com o entendimento que liga políticas públicas de segurança, enquanto políticas criminais, a um posicionamento exclusivamente reativo/repressivo, normalmente pautado no pensamento de combate à violência criminal através da violência institucional, vez que não parece ser esse o tipo de entendimento mais consentâneo em um Estado Democrático de Direito.

Como uma maior aproximação aos ditames da legalidade e da democracia, parece-nos pertinente adotar a diferenciação entre Políticas de Segurança Pública, enquanto atividades a serem desenvolvidas na esfera do controle social formal, fortemente agregadas à atividades tipicamente policiais - atuação policial stricto sensu - e Políticas Públicas de Segurança, cujas atividades devem ser muito mais amplas englobando as diversas ações nas esferas governamentais e não governamentais, mas que estejam voltadas para enfrentar e, se possível, solucionar os diversos problemas afetos à criminalidade e à violência fora do eixo reativo/repressivo ${ }^{23}$.

Partimos do pressuposto de que as Políticas Públicas de Segurança estão mais próximas aos anseios democráticos, assim como mais afinadas com os aspectos legais, do que as Políticas de Segurança Pública que, embora necessárias, estão mais voltadas para as ações de enfrentamento, caracterizadas por planejamentos verticais e, amiúde, apontadas como de difícil controle de legalidade quando de suas concretizações.

Por essa via, entendemos que a governamentalidade democrática implica, também, uma relação social entre agentes públicos e comunidade ${ }^{24}$, que

\footnotetext{
${ }^{23}$ Imprescindível sobre esta temática cfr. Oliveira (2002, p. 46 e ss.). Cfr., também, Guimarães (2013).

${ }^{24}$ No entendimento de Félix (2008) oriundo de pesquisa realizada nas favelas da cidade de Marília, no Estado de São Paulo, quando investigou a relação dos moradores da favela com seu local de habitação:
} 
através da troca de experiências buscam alternativas com o objetivo de controlar as diversas formas de violência mediante práticas sociais instauradoras, como o incremento de ações educativas que estimulem relações interpessoais amistosas, orientadas pela não violência, pela recuperação da ambiência de convivência das comunidades, representadas por uma completa reestruturação urbana, dentre outras medidas não afetas ao controle social formal, ou seja, não coercitivas .

Pela via da prevenção, portanto, quer seja primária, secundária ou terciária, na qual o combate a comportamentos delitivos visa a não reincidência de tais ações danosas ou pelo combate da criação de oportunidades que estimulem as pessoas a delinquir ou, ainda, ao enfrentamento da progressão criminosa, na qual as pessoas acabam por cometer delitos cada vez mais graves, várias políticas públicas compartilhadas entre o poder público e as comunidades podem ser efetivadas, com consequências diretas nos índices de encarceramento ${ }^{25}$.

Em tal perspectiva já existem vários trabalhos que apontam a confiança e a solidariedade entre os moradores como pressuposto para que uma vizinhança consiga um efetivo controle social informal, traduzido na predisposição dos residentes locais em agirem para obtenção do bem comum. Desse modo, a partir da coesão social obtida, deve a comunidade alcançar uma efetiva interlocução entre seus representantes e a esfera pública de poder, localizada fora dos limites da comunidade, em prol da contenção do avanço dos elementos distintivos de "oportunidade criminal"26. (SAMPSON ET AL, 1997)

Percebemos, pois, a importância do resgate de uma ambiência onde prepondere o civismo e, consequentemente, a civilidade, vez que esta deve ser a base na qual, paulatinamente, se oportunize a construção de uma convivência humana coletiva possível, a partir de exigências pautadas no equilíbrio e proporcionalidade entre o que se exige e os meios disponibilizados para

\footnotetext{
"Por tudo o que se viu, ratificamos a necessidade de ver, ouvir, dar voz e vez aos segmentos historicamente apartados das decisões. Gestores públicos devem estar atentos às formas como as pessoas leem e sentem o ambiente urbano. O espaço, apesar de ser um conteúdo para todos, também é restritivo e determina uma geometria de ocupação, em função de questões estruturais como as socioeconômicas (espaço de ricos e pobres) e em função de manifestações criminais, configurando-se em espaços temidos e evitados, independentemente de padrões sociais".

${ }^{25}$ Sobre os diversos níveis de prevenção, especificamente, cfr. Garrido Genovês e López Latorre (2005, p. 329 e ss.). Sobre o tema do encarceramento, cfr., em profundidade, Guimarães (2007).

${ }^{26}$ Tal nível de interação entre moradores e o Poder Público foi nominado pela doutrina como "eficácia coletiva", cuja concreção é explicada por Silva e Marinho (2014, p. 72).
} 
cumprimento de tais exigências por parte do poder público. (ORTUÑO RODRIGUEZ, 2010)

Em síntese, partindo-se do modelo original de desorganização social e urbana elaborado pela sociologia de Chicago, é possível vislumbrar que uma parcela dos fenômenos criminais (como p. ex. patrimoniais) é agudizada pela existência de áreas urbanisticamente deterioradas, com baixo status socioeconômico, baixo nível educacional, instabilidade residencial, presença de facções, dentre outros fatores indicados como causa de erosão do tecido social que inviabilizam os controles sociais (formal e informal).

Dessa forma, pela via de políticas públicas de diversos setores há a viabilização de serviços públicos direcionados às necessidades específicas das comunidades, minimizando os efeitos da desestrutura urbana e social, com impacto direto sobre as taxas desta criminalidade setorizada ${ }^{27}$, dando-se ênfase, dessa forma, a ações de prevenção estrutural ${ }^{28}$ e, portanto, com a consequente diminuição dos índices de cometimento de crimes, é rompida a cadeia de atuação do sistema punitivo que, no mais das vezes, leva ao encarceramento.

Em assim atuando, ao desenvolver o Poder Público um novo campo de sociabilidade solidária, privilegiando a participação da sociedade civil na construção de novas e boas práticas comunitárias que estimulem uma reestruturação social fora do contexto repressivo, está o mesmo estimulando a constituição de práticas sociais e políticas que levarão à produção de uma ordem social propícia a alcançar um campo de possibilidades para a montagem de espaços de cidadanias concretas e fluxos efetivos de assistências sociais, refletindo de maneira muito clara, a participação da comunidade nas lutas sociais contra a violência, fortalecendo consequentemente, o Estado Democrático de Direito e o direitos fundamentais ${ }^{29}$.

\footnotetext{
${ }^{27}$ Sobre o tema, em profundidade, Sampson (1986). Cfr. também, Ruiz Rodrigues (2010).

${ }^{28}$ Para Garrido Genovês e López Latorre (2005, p. 295), "a prevenção estrutural é aquela que fundamenta as causas da delinquência no mal funcionamento das instituições sociais, (a família, a escola, o mercado de trabalho, etc.) objetivando, deste modo, por ênfase na mudança de atitude na direção e nas práticas de prestação de serviços dentro das organizações da comunidade".

${ }^{29}$ Esta é a nova proposta do CNJ que protagoniza um promissor projeto iniciado no final de 2018 , denominado "Justiça Presente". Trata-se de uma parceria inédita com o Programa das Nações Unidas para o Desenvolvimento (PNUD) que coloca o Judiciário como protagonista no enfrentamento do estado de coisas inconstitucional apontado pelo Supremo Tribunal Federal em 2015 (ADPF n ${ }^{\circ}$ 347/DF). O programa também é resultado do engajamento do Depen e do Ministério de Justiça e Segurança Pública,
} 
Deste modo, pensamos ser de bom alvitre alargar o campo de possibilidades das políticas públicas, para muito além do extermínio da violência que tem por referência a insegurança e o medo incutidos na sociedade pela crescente onda de violência criminal urbana e que traz a reboque a intensa pressão social e midiática pelo aumento de medidas de cunho exclusivamente repressivos, ${ }^{30}$ para que não se venha a perder as referências que norteiam o estabelecimento e a vigência de um Estado Democrático de Direito.

Considerando ser um fenômeno complexo, outros atores e formas têm que ser envolvidos no âmbito do combate à violência urbana, preferencialmente encarando tal fenômeno a partir de suas características mais amplas, que interligam de maneira definitiva as categorias violência criminal e violência estrutural, o que, necessariamente, conduz a priorização de ações preventivas e inclusivas em detrimento das reativas e repressivas $^{31}$.

Por essa via, qualquer política pública que objetiva combater a violência urbana setorizada, obrigatoriamente, tem que envolver a comunidade alvo de tais intervenções na elaboração, planejamento e execução daquilo que vai ser posto em prática naquela comunidade, em razão mesmo do respeito ao ditame constitucional que dispõe ser a Segurança Pública um dever do Estado e responsabilidade de todos os $\operatorname{cidadãos}^{32}$.

que realizou um aporte financeiro para o desenvolvimento de estratégias que abordam as causas do problema de forma sistêmica, buscando resultados visíveis em curto e médio prazo. Entre os principais diferenciais do programa, estão a preocupação com todo o ciclo penal, a consolidação de experiências anteriores exitosas do $\mathrm{CNJ}$ e o desenho de intervenções customizadas à realidade de cada estado, construídas em estreita colaboração com os atores locais para garantir a efetividade e sustentabilidade das soluções, minimizando os efeitos deletérios do cárcere. Além disso, o protagonismo do Judiciário é incentivado na mesma proporção da construção de redes envolvendo os demais atores da execução penal, como Executivo, sistema de Justiça e sociedade civil. Um dos eixos do programa em desenvolvimento é combater o superencarceramento por entender que esta é uma das vias mais improdutivas de enfrentamento à violência, fortalecendo as práticas restaurativas, o bom andamento das audiências de custódia, construção de redes assistenciais, alternativas penais e desenvolvimento de cidadanias dentro e fora dos presídios. (https://www.cnj.jus.br/sistema-carcerario-e-execucao-penal/justica-presente/sobre-oprograma)

${ }^{30}$ Um aprofundado estudo sobre a temática pode ser encontrado em Lima, Misse e Miranda (2000).

${ }_{31}^{31}$ Assim, Baratta (1999).

${ }^{32}$ Cfr. Art. 144 da Constituição da República Federativa do Brasil. Sobre os novos paradigmas da segurança, necessário citar Clemente (2015, p. 90): "Certamente, garantir a segurança é uma responsabilidade do governo de cada Estado, e também da sociedade: a segurança é hoje responsabilidade de todos. E é da responsabilidade de todos, porque a segurança suporta a liberdade cívica e o bem-estar dos concidadãos, bem como a estabilidade do Estado. Na verdade, as sociedades que se fazem responsáveis por sua segurança são sociedades mais livres". 
Nessa linha estão sendo desenvolvidos estudos denominados de prevenção comunitária, nos quais os cidadãos assumem um papel de protagonistas na gestão de suas próprias demandas de segurança, através da reconstrução do controle social do espaço no qual habitam. Assim, a partir de uma diminuição na capacidade de decisão das instâncias políticas e, consequentemente, pelo aumento da proatividade e dinamização da responsabilidade cidadã, os integrantes da comunidade assumem parte das responsabilidades frente ao delito, principalmente, na seara de resgate da efetividade do controle social informal sobre os indivíduos, pela via da recuperação dos espaços públicos e forte controle comunitário das incivilidades ${ }^{33}$.

O certo é que, independentemente da nomenclatura utilizada, ou seja, prevenção comunitária, segurança cidadã, orçamento participativo, dentre tantos outros termos que se inserem na temática, faz-se necessário ampliar a participação dos membros das comunidades no planejamento, na execução e no controle das atividades da segurança pública; é preciso, dessarte, fortalecer a democracia fazendo com que os cidadãos e as organizações da sociedade civil assumam sua parcela de responsabilidade na busca de solução dos problemas existentes em tal âmbito ${ }^{34}$.

Por outro lado, como um forte argumento a ser utilizado na defesa do desenvolvimento de Políticas Públicas alternativas ao modelo até agora utilizado no Brasil na área da segurança pública, que dá prioridade e se baseia quase que exclusivamente no eixo reativo/repressivo, devemos analisar o custo financeiro com a realização destas Políticas Públicas postas em andamento mais recentemente e os resultados obtidos com estas práticas que, via de regra, enxergam a segurança pública como algo que só pode ser melhorado através do melhor aparelhamento dos órgãos por ela responsáveis.

De acordo com o Fórum Brasileiro de Segurança Pública ${ }^{35}$, em 2017 o Brasil gastou o equivalente a $\mathrm{R} \$ 84,7$ bilhões de reais com Segurança Pública, sendo 9,7 bilhões em âmbito da União, 5,1 bilhões em âmbito municipal e 69,8 bilhões em nível estadual, sem conseguir nenhuma redução nas taxas de criminalidade no país, pelo

\footnotetext{
${ }^{33}$ Sobre o tema, detalhadamente, cfr. Medina Ariza (2010).

${ }_{35}^{34}$ Assim, Mesquita Neto (2011). Cfr., também, Moran et al (2008).

35 Dados disponíveis em: http://www.forumseguranca.org.br/wpcontent/uploads/2019/02/Infografico_an12_atualizado.pdf.
} 
contrário, no último atlas da violência $(2019)^{36}$, o Brasil acusa mais de 65.000 homicídios em 2017, dentre outras taxas de criminalidade em ascensão.

De posse dos dados acima relatados, forçoso reconhecer que o aumento do efetivo policial, mais viaturas, mais armas, mais investimento em inteligência, mais treinamento, enfim, mais aparelhamento dos órgãos do sistema, dentre muitas outras medidas de cunho reativo/repressivo, não irão, isoladamente, resolver o problema da criminalidade, haja vista que, como já dito, necessário que sejam desenvolvidas políticas públicas preventivas e inclusivas concomitantes para enfrentamento das violências.

Numa perspectiva muito mais abrangente da complexidade criminal, defende-se a ideia que ao lado do melhor aparelhamento das Instituições que fazem parte do Sistema Formal de Controle Social, assim como, através de um redimensionamento dos gastos públicos securitários, deve-se buscar, no âmbito das políticas criminais, o desenvolvimento de políticas públicas que priorizem o combate à violência estrutural e, como via absolutamente certa de consequência, a diminuição da violência criminal, com impactos absolutamente certos na diminuição dos índices aprisionamento no nosso país.

\section{O PAPEL DOS MUNICÍPIOS NO DESENVOLVIMENTO DAS POLÍTICAS PÚBLICAS DE SEGURANÇA}

A Constituição Federal de 1988 trouxe fundamentos e orientações - vez que é tida como uma Constituição programática - para uma maior intervenção social por parte do poder público, vez que ampliou o leque de direitos sociais e o campo da proteção social sob a responsabilidade do Estado, com destaque para as políticas, beneficiários e benefícios ${ }^{37}$.

Assim sendo, os direitos sociais que hodiernamente estão assegurados na Constituição Federal devem ser analisados, priorizados e implementados pelo poder público - de acordo com as situações concretas que se afiguram e com as limitações

\footnotetext{
${ }^{36}$ Disponível em:

http://www.ipea.gov.br/portal/images/stories/PDFs/relatorio_institucional/190605_atlas_da_violencia_20 19.pdf

${ }^{37}$ Sobre o tema, cfr. Jaccoud e Cardos Júnior (2005).
} 
orçamentárias -, por meio de políticas públicas sociais e econômicas que garantam, que efetivem o acesso universal aos direitos fundamentais lá previstos, assegurando uma igualdade material mínima entre seus titulares ${ }^{38}$.

Um dos mecanismos apropriados para alcance de tal desiderato seriam as políticas públicas a serem desenvolvidas, prioritariamente, pelos Poderes Executivos Municipais, Estaduais e Federal.

Defendemos, pois, a ideia de que as políticas públicas servem para dar concretude aos direitos fundamentais previstos na Constituição Federal, entretanto, para que sejam implementadas necessitam do interesse dos políticos democraticamente eleitos, haja vista ser de suas competências o planejamento e execução destas, ou seja, é pela via da discricionariedade que os programas de governo são pensados e executados, pois os governantes gozam da liberdade para definição, de conteúdo e momento para execução das políticas públicas.

Ante tais exigências e pela linearidade do que neste trabalho temos articulado, ou seja, intervenções ambientais de cunho social e urbanístico como políticas públicas para enfrentamento da violência - estrutural e criminal - e criminalidade $^{39}$, entendemos que o caminho a ser seguido passa, sem a menor sombra de dúvidas, pelo aumento da participação municipal ${ }^{40}$, capaz de incrementar resultados positivos em nível global de segurança pública ${ }^{41}$ com impactos diretos nos níveis de encarceramento no país.

Importante frisar que as políticas públicas em âmbito municipal aqui propostas, em nenhuma hipótese objetivam oposição ou substituição às necessárias medidas de cunho repressivo policial, de melhoria do sistema formal de controle social, de investimentos massivos em educação, dentre outras políticas afetas ao disciplinamento da sociedade, vez que temos plena consciência de que as medidas interventivas de cunho social e urbanístico demandam tempo para apresentarem

\footnotetext{
${ }^{38}$ Sobre Políticas Públicas, por todos, Moran et al (2008).

${ }^{39}$ Sobre a importância do exercício da cidadania em tal processo de intervenções de cunho social e urbanístico, como forma de consolidação dos direitos assegurados constitucionalmente, em profundidade, Andrade (2003). Cfr., também, Baratta (2009).

${ }^{40}$ Sobre o tema, cfr. Guimarães e Pereira (2014, p. 825 e ss.). Cfr., também, Lima et al (2014) e Beato Filho (2012).

${ }^{41}$ Assim, Soares (2003).
} 
resultados e devem ser implementadas em concomitância com tais medidas de ordem e $\operatorname{disciplina}^{42}$.

Concretamente estamos a falar de intervenções urbanísticas que devem ser levadas a efeito pelos órgãos municipais, tais como a organização e fiscalização das atividades de trânsito e transporte, a recuperação e posterior preservação das áreas públicas fisicamente degradadas, a conservação de espaços públicos de lazer com vistas à integração social local, como parques, praças, espaços culturais, quadras esportivas, a proteção contra a invasão e apropriação indevida dos espaços públicos de uso comum, a fiscalização da comercialização de alimentos e bebidas, a autorização para realização de eventos públicos e a fiscalização rigorosa dos mesmos, dentre tantas outras atividades inerentes a tais órgãos e que tem impacto direto em níveis de criminalidade e, portanto, na esfera da segurança pública ${ }^{43}$.

Ademais, intervenções no âmbito do controle social informal, como o desenvolvimento de projetos executados pela própria comunidade ou através de organizações não governamentais, com ênfase em grupos reflexivos e redes assistenciais, com enfoque especial na juventude assediada pelas facções criminosas, no sentido de compreender criticamente a dinâmica criminal na e da comunidade, explorar meios de intervenção próprios, de acordo com aquela realidade específica e explorar e direcionar as demandas ao poder público atinentes ao diagnóstico traçado.

Portanto, reafirmamos a possibilidade de qualquer ente federativo atuar especificamente em determinada área, através de projetos elaborados com as finalidades acima expostas, é fácil reconhecer que o município - no qual a área objeto de maior atenção em razão dos níveis de violência apresentados está incorporada - é o ente federativo mais apropriado para levar a efeito o tipo de intervenção aqui proposta.

O Município é, dentre todos os organismos de gestão política, aquele que está mais próximo do cidadão, é a área geográfica que sofre os efeitos diretos da violência, oriundos dos bairros que lhe integram por serem social e urbanisticamente desestruturados, além do que somente está apto a operar, em questões de segurança pública, nesse tipo de intervenção aqui proposta, haja vista que as Guardas Municipais,

\footnotetext{
${ }^{42}$ Sobre estratégias de prevenção criminal, por todos, Welsh e Farrington (2016).

${ }^{43}$ Sobre o assunto, cfr. Kahn (2005) e Carmona (2014, p. 38), para quem: “...o lazer é poderoso aliado na diminuição das tensões sociais, dificultando o surgimento da criminalidade, principalmente em relação ao segmento infanto-juvenil, maiores vítimas e autores da violência urbana. [...] vários estudos comprovaram que a efetivação do direito ao lazer ao jovem constitui forte instrumento no combate à violência urbana".
} 
de acordo com o artigo 144, $\S 8^{\circ}$, da Constituição Federal, ainda não tem respaldo jurídico para fazerem intervenções repressivas ${ }^{44}$.

Um dos grandes avanços em matéria de Segurança Pública de viés preventivo foi a previsão constante no Fundo Nacional de Segurança Pública - FNSP, criado pela Lei 10.201/2001, de criação de Conselhos Municipais de Segurança, que permitem à comunidade ter acesso e participação ao processo decisório sobre as prioridades e a forma como os recursos públicos devem ser alocados, no que pertine às necessidades locais de Segurança Pública ${ }^{45}$. Tais Conselhos representam um imprescindível elo de ligação entre as necessidades específicas da comunidade e os órgãos de planejamento, gestão e execução de políticas setorizadas de Segurança Pública.

Já no ano de 2000, quando do lançamento do Plano Nacional de Segurança Pública - PNSP, diversos pontos de atuação do mesmo previam a adoção das medidas aqui defendidas, assim como, a imprescindível atuação dos Municípios no âmbito da Segurança Pública ${ }^{46}$.

Por fim, para reforçar o entendimento aqui defendido, importante destacar que a minuta do documento denominado Política Nacional de Segurança Pública PNASP $^{47}$ com previsão para ser iniciado em fevereiro de 2018, esteve disponível no site do Ministério da Justiça e Segurança Pública do Governo Federal para consulta pública e, consequentes, sugestões, privilegiando o papel dos Municípios nas políticas de prevenção e combate ao crime pela via não repressiva.

\section{APONTAMENTOS FINAIS}

Diante dos argumentos traçados no presente trabalho que agora se finda, concluímos que são pertinentes os ensinamentos provenientes da Escola Sociológica de Chicago, especificamente aqueles que inter-relacionam desestruturação social à

\footnotetext{
${ }^{44}$ Sobre a temática, por todos, cfr., Lima et al (2014).

${ }^{45}$ Em 06/01/17, um novo Plano Nacional de Segurança Pública foi lançado pelo Governo do Presidente Michel Temer, reconhecendo o importante papel que os municípios podem desempenhar no âmbito do combate à criminalidade.

${ }^{46}$ Cfr. (PNSP, 2000).

${ }^{47}$ A Política Nacional de Segurança Pública (PNaSP, 2018) é o conjunto de princípios, diretrizes, objetivos que condicionará a estratégia de segurança pública a ser implementada pelos três níveis de governo de forma integrada e coordenada, visando à preservação da vida, à manutenção da ordem pública, ao meio ambiente conservado a garantia da incolumidade das pessoas e do patrimônio, o enfrentamento e prevenção à criminalidade e à violência em todas as suas formas, assim como o engajamento da sociedade, a transparência e publicidade das boas práticas.
} 
desestrutuação urbana e ambas à determinado tipo de criminalidade, devendo ser aprofundados estudos específicos entre tais conexões para que melhor sejam traçados diagnósticos localizados e elaboradas políticas públicas condizentes com tal realidade.

Verificamos, ainda que de forma primária, que entre as mais variadas possibilidades para enfrentamento da violência, está o desenvolvimento de políticas públicas preventivas que reflitam inclusão social, quer pelo resgate dos vínculos e valores sociais e fortalecimento das cidadanias, quer pela recuperação das áreas degradadas, em obediência ao que prevê a Constituição Federal como direitos fundamentais de todo cidadão e que tais políticas sejam efetivadas.

Por fim, acreditamos que pela via da efetivação de políticas públicas de segurança preventiva e inclusivas, preferencialmente levadas a efeito, como dito acima, pelos setores municipais, maiores serão as possibilidades de enfrentamento da violência estrutural e, por via direta de consequência, da violência criminal, com impacto direto na diminuição dos níveis de encarceramento no país.

\section{REFERÊNCIAS}

ADORNO, Sérgio. Violência urbana, justiça criminal e organização social do crime. São Paulo: NEVI/USP, 1990.

ANDRADE, Luciana Teixeira de, SOUZA, Dalva Borges de, FREIRE, Flávio Henrique Miranda de A. (Orgs.) Homicídios nas regiões metropolitanas. Rio de Janeiro: Letra Capital, 2013.

ANDRADE, Vera Regina Pereira. Sistema penal máximo X cidadania mínima: códigos da violência na era da globalização. Porto Alegre: Livraria do Advogado, 2003.

BARATTA, Alessandro. Criminologia crítica e crítica do Direito Penal: introdução à sociologia do direito penal. Tradução de Juarez Cirino dos Santos. 2. ed. Rio de Janeiro: Freitas Bastos, 1999.

BATELLA, Wagner Barbosa, DINIZ, Alexandre Magno Alves. Análise espacial dos condicionantes da criminalidade violenta no Estado de Minas Gerais. 2010. Disponível em: http://www.scielo.br/pdf/sn/v22n1/11.pdf Acesso em 08/02/2018.

BEATO FILHO, Claudio Chaves, Crime e cidades. Belo Horizonte: Editora UFMG, BLUMER, Herbert. Simbolic interacionism: perspective and method. Berkeley: University of California Press, 1986.

BRAGA, Adriana. GASTALDO, Édison. O legado de Chicago e o estudo de recepção, usos e consumos midiáticos. Revista FAMECOS, Porto Alegre, no 39, ago. 2009, p. 78-84.

BURGESS, Ernest W. O crescimento da cidade: introdução a um projeto de pesquisa, in: PIERSON, Donald. Estudos de Ecologia Humana (org.). São Paulo: Martins, 1970, p. 353-368. 
BURSIK JR., Robert J. Social disorganization and theories of crime and delinquency: problems and prospects. Criminology, v. 26, issue 4, novembro de 1988, p. 519-552. Disponível em: http://onlinelibrary.wiley.com/doi/10.1111/j.17459125.1988.tb00854.x/abstract Acesso em 01/03/2018.

CABRAL DE LIRA, Anneliese Heyden. Avaliação da qualidade de vida urbana dos condomínios horizontais da cidade de João Pessoa - PB. 2014. Dissertação (Mestrado em Direito) - Universidade Federal da Paraíba. João Pessoa, 2014.

CAPLAN, Joel. Focus on place, not people to prevent crime. Youtube, 25 de abril de 2016. Disponível em: https://www.youtube.com/watch?v=5hKWLY11Zrs\&t=32s. Acesso em 18/02/2018.

CARMONA, Paulo Afonso Cavichioli. Violência X Cidade. O papel do Direito Urbanístico na violência urbana. São Paulo: Marcial Pons, 2014.

CASTELETTO, Hugo Santana. Estrutura socioespacial de Maringá e os territórios de criminalidade. 2014. Dissertação (Mestrado em Direito) - Universidade Estadual de Maringá. Maringá, 2014.

CERQUEIRA, Daniel; LOBÃO, Waldir. Determinantes da criminalidade: arcabouços teóricos e resultados empíricos. Revista de Ciências Sociais, vol. 47, n. 2, 2004, p. 233-269.

CHICAGO AREA PROJECT. Disponível em http://www.chicagoareaproject.org/aboutus Acesso em 22/02/2018.

CLEMENTE, Pedro José Lopes. Cidadania, Polícia e Segurança. Lisboa: ISCPSI, 2015.

COHEN, Albert K. Delinquent boys: the culture of the gang. In: NEWBURN, Tim. (Org.) Key readings in criminology. London: Willan Publishing, 2009, p. 194-198.

COULON, Alain. A Escola de Chicago. Campinas, São Paulo: Papirus, 1995.

DELGADO, Rodrigo Mendes. Espaços urbanos e criminalidade: um estudo do ambiente urbano como fator criminogênico. 2014. Disponível em: https://jus.com.br/artigos/35064/espacos-urbanos-e-criminalidade Acesso em 17 de fevereiro de 2018.

DEWEY, John. Disponível em: https://deweypragmatismo.wordpress.com/sobre-johndewey/ Acesso em 01/02/2018.

DIAS, Jorge de Figueiredo. ANDRADE, Manuel da Costa. Criminologia - O homem delinquente e a sociedade criminógena. $2^{\mathrm{a}}$ reimpressão. Coimbra: Coimbra Editora, 1997.

DINIZ, Alexandre M. A. Migração, desorganização social e violência urbana em Minas Gerais. 2005. Disponível em http://revistas.ufpr.br/raega/article/view/3443 Acesso em 05/02/2018.

EVANGELISTA, Felipe Camelo de Freitas. A criminalidade e o planejamento ambiental urbano. Veredas do Direito: Direito Ambiental e Desenvolvimento Sustentável, Belo Horizonte, v. 9, n. 17, dez. 2012. Disponível em: http://www.domhelder.edu.br/revista/index.php/veredas/article/view/245 Acesso em: 09/02/18.

FELGUERAS Sérgio. Geração à rasca. Lisboa: Chiado Editora, 2016.

FELIX, Sueli Andruccioli. A Geografia do Crime: interdisciplinaridade e relevâncias. Marília: UNESP/Publicações, 2002.

. Favelas em foco: uma contribuição às Políticas Públicas Municipais.

\begin{tabular}{lllll}
\hline Revista & LEVS. & n. & 2008. & Disponível em:
\end{tabular}


http://www2.marilia.unesp.br/revistas/index.php/levs/article/view/1088 acesso em 24 de novembro de 2018.

FERREIRA, Ignez Costa Barbosa, PENNA, Nelba Azevedo. Território da violência: um olhar geográfico sobre a violência urbana. Revista da GEOUSP - Espaço e Tempo. São Paulo, n. 18, 2005, p. 155-168.

FREITAS, Wagner Cinelli de Paula. Espaço urbano e criminalidade: lições da Escola de Chicago. São Paulo: IBCCRIM, 2002.

GARRIDO GENOVÊS, Vicente; LÓPES LATORRE, Maria Jesús. La prevención de la delincuencia: el enfoque de la competencia social. Valencia: Tirant lo Blanch, 1995. GUIMARÃES, Claudio Alberto Gabriel. Funções da pena privativa de liberdade no sistema penal capitalista. 2 ed., Rio de Janeiro: Revan, 2007.

Reflexões acerca do controle social formal: rediscutindo os fundamentos do direito de punir. Revista da Faculdade de Direito da UERJ-RFD. Rio de Janeiro, v. 1, n. 23, 2013. Disponível em: http://www.epublicacoes.uerj.br/index.php/rfduerj/article/view/4894 Acesso em 02 de fevereiro de 2018.

; PEREIRA, Paulo Fernando Soares. Reflexões a respeito da necessidade de participação dos Municípios na formulação e implementação de políticas de segurança pública. Revista Quaestio Iuris, v. 07, n. 02, Rio de Janeiro, 2014. p. 812-839.

JACCOUD, Luciana; CARDOSO JR., José Celso. Políticas Sociais no Brasil: Organização, abrangência e tensões da ação estatal. In: JACCOUD, Luciana (org.) Questão social e políticas sociais no Brasil contemporâneo. Brasília: IPEA, 2005.

JOAS, H. Interacionismo simbólico. In: GIDDENS, A. \& TURNER, J. (Orgs.) Teoria Social Hoje. São Paulo: Editora UNESP, 1999, p. 127-174.

KAHN, Tulio. Indicadores em prevenção municipal de criminalidade. In: SENTO-SÉ, João Trajano (org.). Prevenção da violência: o papel das cidades. Rio de Janeiro: Civilização Brasileira, 2005.

LIMA, Patrícia Verônica P. S., SOUSA, Janaildo Soares de, ARAUJO SOBRINHO, Adauto Morais de, FAUSTINO, Jennifer Cícera dos Santos; CASIMIRO FILHO, Francisco. Gestão Municipal da Segurança Pública: Responsabilidade dos municípios brasileiros no combate a violência. Revista de Políticas Públicas, São Luís, v. 18, n. 2. Jul./dez. 2014, p. 399-414.

LIMA, Renato Sérgio de. BUENO, Samira; MINGARDI, Guaracy. Estado, polícias e segurança pública no Brasil. Revista Direito GV. São Paulo, v. 12, n. 1, jan./abr. 2016, p. 49-85.

LIRA, Pablo. Análise dos crimes violentos e da tipologia socioespacial da Região Metropolitana da grande Vitória - RMGV. In: Anais do VII Congresso Brasileiro de Geógrafos. Vitória-ES, 2014.

. Geografia do crime. Estudo do Índice de Violência Criminalizada - IVC e da tipologia socioespacial. E-metropolis, ano 23, n. 5, dez. 2015. Disponível em: http://emetropolis.net/system/artigos/arquivo_pdfs/000/000/175/original/emetropolis_n2 3 art1.pdf?1450464274 Acesso em 16/02/2018.

MASSENA, Rosa Maria Ramalho. Distribuição especial da criminalidade violenta na região metropolitana do Rio de Janeiro. Revista Brasileira de Geografia, Rio de Janeiro, v. 48, n. 3, p. 285-330, jul./set. 1986.

MEAD, George Herbert. Mind, self and society from the standpoint of a social behaviorist. Chicago: University of Chicago Press, 1934. 
MEDINA ARIZA, J. "Políticas de seguridad ciudadana en el contexto urbano y prevención comunitaria. La experiencia anglosajona", In: Revista Electrónica de Ciencia Penal y Criminología, n. 12, v. 02, 2010, p. 1-36.

MELHEM, Patrícia Manente. Cidade grande, mundo de estranhos: Escola de Chicago e "comunidades guarda-roupa". Disponível em: https://jus.com.br/artigos/24879/cidade-grande-mundo-de-estranhos-escola-de-chicagoe-comunidades-guarda-roupa/2 acesso em 10/02/2018.

MELO, Silas Nogueira de, MATIAS, Lindon Fonseca. Geografia do crime e criminologia ambiental: teorias da desorganização social e atividade de rotina. 2015. Disponível em: http://www.enanpege.ggf.br/2015/anais/arquivos/2/38.pdf Acesso em 05/02/2018.

MESQUITA NETO, Paulo de. Ensaios sobre Segurança Cidadã. São Paulo, Quartier Latin/FAPESP, 2011.

MISSE, Michel. "Cinco teses equivocadas sobre a criminalidade urbana no Brasil: uma abordagem crítica, acompanhada de sugestões para uma agenda de pesquisas". Série Estudos, n. 91, Rio de Janeiro, 1995. Disponível em: https://www.tigweb.org/images/resources/tool/docs/1837.pdf Acesso em:25/02/2018. MORAN, Michel, REIN, Martin, GOODIN, Robert F. The Oxford Handbook of Public Policy. Oxford: Oxford University Press, 2008.

NASCIMENTO, Edna Maria Magalhães do. Pragmatismo: uma filosofia da ação. 2010.

Disponível

em: http://leg.ufpi.br/subsiteFiles/ppged/arquivos/files/VI.encontro.2010/GT.20/GT_20_01_ 2010.pdf Acesso em 05/02/2018.

OLIVEIRA, Ana Sofia Schimidt de. Políticas Públicas de Segurança e Políticas de Segurança Pública: da teoria à prática. In: Das políticas de segurança pública às políticas públicas de segurança. INSTITUTO LATINO AMERICANO DAS NAÇÕES UNIDAS PARA A PREVENÇÃO DO DELITO E TRATAMENTO DO DELINQÜENTE. São Paulo, 2002. Disponível em: http://www.observatoriodeseguranca.org/files/livro-prevdocrime\%20ILANUD.pdf acesso em 24 de novembro de 2018

ORTUÑO RODRIGUEZ, Alicia Ester. Civismo y convivencia municipal. Barcelona: Editorial Bayer, 2010.

PARK, Robert Ezra. On Social Control and Collective Behavior. Chicago: University of Chicago Press, 1967.

, BURGESS, Ernest W. Introduction to the science of sociology. Chicago: The University of Chicago Press, 1921.

. MCKENZIE, R. The City. Suggestions for investigation of

human behavior in the urban environment. Chicago: Midway, 1984.

PLANO NACIONAL DE SEGURANÇA PÚBLICA. 2000. Disponível em: http://www.observatoriodeseguranca.org/files/PNSP\%202000.pdf Acesso em: 21 de fevereiro de 2018.

PLANO NACIONAL DE SEGURANÇA PÚBLICA. 2017. Disponível em: http://www.justica.gov.br/news/plano-nacional-de-seguranca-preve-integracao-entrepoder-publico-e-sociedade/pnsp-06jan17.pdf Acesso em 21 de fevereiro de 2018. POLÍTICA NACIONAL DE SEGURANÇA PÚBLICA. 2018. Disponível em: http://www.justica.gov.br/news/politica-nacional-de-seguranca-

publica/minuta_pnasp.pdf Acesso em 22 de fevereiro de 2018.

RAMOS, Edvaldo Fernandes. A cidade pensada teoricamente. Caderno de Geografia, v. 25, n. 44, 2015. 
SAMPSON, R. J.; STEPHEN, S. R.; EARLS, F. Neighborhoods and violent crime: a multilevel study of Collective Efficacy. Science, v. 277, 1997, p. 918-24.

RIBEIRO, Eduardo, CANO, Inácio. Civitas, Porto Alegre, v. 16, n. 2, abr./jun. 2016, p. 285-305.

SAMPSON, R. J. Crime in Cities: The Effects of Formal and Informal Social Control. In: TONRY, Michael; NORRIS, N. Crime and Justice, v. 8. Chicago: University of Chicago Press, 1986.

SANTOS, Márcia Andréia Ferreira, Geografia dos crimes violentos em Uberlândia MG. Revista da ANPEGE, v. 12, n. 19, jul./dez. 2016, p. 166-182.

SHAW, Clifford R., McKAY, Henry D. Juvenile delinquency and urban areas - a study of rates of delinquents in relation to differential characteristics of local communities in American cities. Chicago: The University of Chicago Press, 1942.

SILVA, Bráulio; MARINHO, Frederico Couto. Urbanismo, desorganização social e criminalidade. In: Crime, Polícia e Justiça no Brasil. São Paulo: Editora Contexto, 2014, p. 23-29.

SIQUEIRA, Maria da Penha. Industrialização e empobrecimento urbano: caso da grande vitória 1950-1980. Vitória: Edufes, 2001.

SKOGAN, Wesley G. Disorder and crime. In: WELSH, Brandon C., FARRINGTON, Davia P. The Oxford Handbook of Crime Prevention. Oxford: Oxford University Press, 2014, p. 173-188.

SOARES, Luis Eduardo. Novas políticas de segurança pública. Revista de Estudos Avançados, vol.17, n. 47, São Paulo, Jan./Abr. 2003.

SOGAME, M. Rudimentos para o exame da urbanização em sua fase crítica: uma aproximação ao conceito de segregação socioespacial. In: Revista geografares. Vitória: Edufes, n. 2, 2001, p. 95-103.

TANGERINO, Davi de Paiva Costa. Crime e cidade: Violência urbana e a Escola de Chicago. Rio de Janeiro: Lumen Juris, 2007.

TEODÓSIO. Armindo dos Santos de Sousa. Escola de Chicago: heranças para o pensamento social contemporâneo sobre as cidades. Trabalho apresentado no XI Congresso Brasileiro de Sociologia. 1 a 5 de setembro de 2003, UNICAMP, Campinas, São Paulo.

THOMAS, William I. The Unadjusted Girl with cases and standpoint for behavior analysis. New York: Little, Brown \& Co, 1923.

ZNANIECKI, F. The polish peasant in Europe and America.

Nova York: Knopf, 1927.

WELSH, Brandon C., FARRINGTON, David P. The Oxford Handbook of Crime Prevention. Oxford: Oxford University Press, 2016. 